\title{
Exploring physical and chemical properties in new multifunctional indium-, bismuth-, and zinc-based 1D and 2D coordination polymers $\dagger$
}

\author{
G. E. Gomez, (D)*a,b R. F. D'vries, (D)*c,d D. F. Lionello, ${ }^{a, e}$ L. M. Aguirre-Díaz, (D) ${ }^{f}$

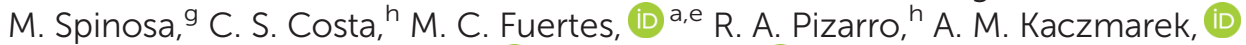 \\ J. Ellena, ${ }^{d}$ L. Rozes, ${ }^{j}$ M. Iglesias, (D ${ }^{f}$ R. Van Deun, (D) ${ }^{i}$ C. Sanchez, ${ }^{\star j}$ M. A. Monge ${ }^{f}$ and \\ G. J. A. A. Soler-Illia (DD $* b$
}

\begin{abstract}
Main group element coordination polymers (MGE-CPs) are important compounds for the development of multifunctional materials. However, there has been a shortage of studies regarding their structural, optical, catalytic, mechanical, and antibacterial properties. This work presents an exhaustive study of a set of crystalline MGE-CPs obtained from bismuth and indium metals and iminodiacetate, 1,2,4,5-benzenetetracarboxylate, and 2,2'-bipyridine as building blocks. An in-depth topological analysis of the networks was carried out. Additionally, nanoindentation studies were performed on two representative low-dimensional compounds in order to find the relationships between their structural features and their intrinsic mechanical properties (hardness and elasticity). The solid-state photoluminescence (SSPL) properties were also studied in terms of excitation, emission, lifetimes values, and CIE chromaticites. Moreover, the heterogeneous catalytic activities of the compounds were evaluated with the cyanosilylation reaction using a set of carbonylic substrates under solvent-free conditions. Finally, the inhibitory effect of the BiCPs on the growth of microorganisms such as Escherichia coli, Salmonella enterica serovar Typhimurium, and Pseudomonas aeruginosa, which are associated with relevant infectious diseases, is reported.
\end{abstract}

${ }^{a}$ Gerencia de Quimica, Centro Atómico Constituyentes, Comisión Nacional de Energía Atómica, Av. Gral. Paz 1499, 1650 San Martin, Buenos Aires, Argentina. E-mail: gegomez@unsl.edu.ar

${ }^{b}$ Instituto de Nanosistemas. Universidad Nacional de San Martín, Av. 25 de Mayo 1021, San Martin, Buenos Aires, Argentina

${ }^{c}$ Facultad de Ciencias Básicas, Universidad Santiago de Cali, Calle 5 \# 62-00, Cali, Colombia.E-mail: gsoler-illia@unsam.edu.ar

${ }^{d}$ Instituto de Física de São Carlos, Universidade de São Paulo, CP. 369, 13560-970 São Carlos, SP, Brasil. E-mail: richard.dvriesoo@usc.edu.co ${ }^{e}$ Instituto Sabato, UNSAM-CNEA, Av. Gral. Paz 1499, B1650KNA San Martín, Buenos Aires, Argentina

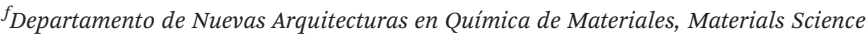
Factory, Instituto de Ciencia de Materiales de Madrid-Consejo Superior de Investigaciones Cientificas, Sor Juana Inés de la Cruz 3, Madrid 28049, Spain ${ }^{g}$ Programa Nacional de Gestión de Residuos Radiactivos-PNGRR, Comisión Nacional de Energía Atómica, Av. Gral. Paz 1499, 1650 San Martin, Buenos Aires, Argentina ${ }^{h}$ Departamento de Radiobiología, Gerencia de Química Nuclear y Ciencias de la Salud, Comisión Nacional de Energía Atómica, Av. Gral. Paz 1499, 1650 San Martin, Buenos Aires, Argentina

${ }^{i} L^{3}$ - Luminescent Lanthanide Lab, Ghent University, Department of Chemistry, Krijgslaan 281, Building S3, 9000 Gent, Belgium

${ }^{j}$ UMR 7574 Chimie de la Matière Condensée de Paris, UPMC Univ. Paris 06-CNRS, Collège de France, 11 place Marcelin Berthelot, 75231 Paris Cedex 05, France. E-mail: clement.sanchez@upmc.fr

$\dagger$ Electronic supplementary information (ESI) available: Synthetic procedure details, experimental X-ray powder patterns, TGA and DSC profiles, FTIR spectra, and decay luminescence profiles. CCDC 1561408-1561411. For ESI and crystallographic data in CIF or other electronic format see DOI: 10.1039/c7dt04287f

\subsection{Introduction}

Inorganic-organic hybrid compounds as coordination polymers (CPs) or metal organic frameworks (MOFs) have become the focus of research due to their unique properties such as gas sorption, ${ }^{1}$ optics, ${ }^{2}$ and heterogeneous catalysis. ${ }^{3}$ In comparison with transition metals from the $\mathrm{d}$ and $\mathrm{f}$ block, the main group elements (MGE) have been less explored for designing new coordination compounds. Most of the metal ions have been incorporated into these materials, but only recently have $\mathrm{Bi}^{3+}$-compounds with optical ${ }^{4}$ or catalytic ${ }^{5}$ properties been reported. For this reason, the synthesis and studies related to Bi-CPs are surprisingly scarce.

Particularly, our research has addressed the synthesis of new CPs and MOFs with optical, ${ }^{6}$ mechanical, ${ }^{7}$ catalytic, ${ }^{8-10}$ thermo ${ }^{8,11}$ chemical, ${ }^{6 b}$ and sensing properties ${ }^{12}$ and explored structure-property relationships. Moreover, the catalytic properties of In-CPs have been widely explored by Monge's group, who found exceptional correlations between the structures and their catalytic performances. ${ }^{13}$

Because of its geometrically flexible coordination environments, the trivalent Bi ion can be regarded as a novel node in the construction of CPs. Moreover, bismuth leads to unpredict- 
able and diverse structures because it presents a variety of coordination numbers. In this context, Inge et al. ${ }^{14}$ recently reported an 8-coordinated Bi-MOF constructed from a tricarboxylate linker, revealing an unprecedented topological complexity.

From the point of view of the design of new CPs, during the last decade, iminodiacetic and 1,2,4,5-benzenetetracarboxylic acids have been employed as building blocks for the synthesis of CPs and MOFs as multifunctional platforms. ${ }^{15}$

An increasingly urgent problem has been the antibiotic resistance observed in several pathogenic microorganisms, and diverse strategies have been proposed to overcome the rapid emergence of resistant organisms. ${ }^{16}$ To counteract microbial pathogens, metallic or oxide nanoparticles (NPs) have been developed due to their novel physicochemical properties. ${ }^{16}$ In the case of $\mathrm{Bi}$, different compounds are being used against ulcers and in treatments for gastritis, diarrhoea, and dyspepsia. ${ }^{17}$ Moreover, bismuth derivatives (for example, bismuth subsalicylate and bismuth citrate) have long been used as antimicrobial agents against several bacterial species, particularly Helicobacter pylori, a bacterium responsible for peptic ulcers and gastric cancer. ${ }^{17 e}$ Their antimicrobial activity was observed at relatively high concentrations due to their limited water solubility. ${ }^{18}$ In addition, it has been demonstrated that Bi-NPs reduce biofilm (growth of microorganisms on solid surfaces) formation by bacteria and fungi such as Streptococcus mutans and Candida albicans. ${ }^{19,20}$ Biofilms represent a great problem for industry and human health because they form on a wide variety of surfaces, possess high resistance to antimicrobial agents, and are very difficult to eradicate. ${ }^{21}$

To understand the processability and the mechanical properties of the new materials, nanoindentation studies have recently been adopted. In the pioneering work of Cheetham, ${ }^{22}$ nanoindentation tests have been applied to demonstrate the intrinsic correlations between crystal packing and anisotropic mechanical properties (such as density, stability, and elasticity) in MOF materials.

The present work involves a complete study regarding the synthesis strategies, photophysical characterization, mechanical and catalytic analysis, and antimicrobial activity assay of a set of CPs based on main-group elements (MGE-CPs), or more specifically, two Bi-CPs and one In-CP.

\subsection{Experimental section}

\subsection{Synthesis}

$\left[\mathrm{Bi}(1,2,4,5-\mathrm{BTC})_{0.5}\left(2,2^{\prime}\right.\right.$-bipyridine $\left.)\left(\mathrm{NO}_{3}\right)(\mathrm{DMF})\right]$ (Bi-1), [Bi(IDA) (IDAH)] (Bi-2), [In(IDA)(Cl)] (In-1) and [Zn(1,2,4,5-BTC) ${ }_{0.5}\left(2,2^{\prime}-\right.$ bipyridine) $\left.\left(\mathrm{H}_{2} \mathrm{O}\right)\right]$ (Zn-1), were obtained as crystalline solids under solvothermal conditions using $43 \mathrm{~mL}$ Teflon-lined Parr reactors. The solid reactants and solvents were used as received without purification from Across Organics (1,2,4,5benzenetetracarboxylic acid) and Sigma-Aldrich (2,2'-bipyridine, $\mathrm{Bi}\left(\mathrm{NO}_{3}\right)_{3} \cdot 5 \mathrm{H}_{2} \mathrm{O}, N, N^{\prime}$-dimethylformamide, iminodiacetic acid, $\mathrm{Zn}\left(\mathrm{NO}_{3}\right)_{2} \cdot 6 \mathrm{H}_{2} \mathrm{O}$ and $\mathrm{InCl}_{3}$ ) (see ESI section $\mathrm{S} 1 \uparrow$ for synthesis details).

\subsection{Fourier transform infrared spectroscopy (FTIR)}

FTIR spectra were recorded with a Nicolet Protégé 460 spectrometer in the $4000-400 \mathrm{~cm}^{-1}$ range with 64 scans and a spectral resolution of $4 \mathrm{~cm}^{-1}$ by the $\mathrm{KBr}$ pellet technique. The FTIR spectra and band assignments are displayed in ESI section S2.†

\subsection{Thermal analysis}

Thermogravimetric analysis (TGA) and differential scanning calorimetry (DSC) were performed with Shimadzu TGA-51 and DSC-60 apparatus, respectively, under flowing air at 50 $\mathrm{mL} \min ^{-1}$, at a heating rate of $10{ }^{\circ} \mathrm{C} \min ^{-1}$. TGA and DSC curves are displayed in ESI section $\mathrm{S} 3 . \dagger$

\subsection{Powder X-ray diffraction (PXRD)}

PXRD patterns were obtained with a Rigaku D-MAX-IIIC diffractometer using $\mathrm{CuK} \alpha$ radiation $\left(\lambda_{1}=1.54056 \AA, \lambda_{2}=\right.$ $1.54439 \AA$ ) (see ESI section S4†).

\subsection{Scanning electron microscopy (SEM)}

SEM micrographs were obtained and energy dispersive spectroscopy (EDS) (ESI section S5†) was used with FEI Quanta 200 equipment. Samples were placed on an adhesive carbon tape coated with gold for the observations.

\subsection{Single-crystal structure determination (SCXRD)}

The SCXRD data for compounds Bi-1, Bi-2, and Zn-1 were collected at room temperature (293 K) on a Rigaku XTALAB-MINI diffractometer using MoK $\alpha$ radiation (0.71073 ̊) monochromated by graphite. The In-1 compound was collected at room temperature (296 K) with a Bruker APEX-II CCD diffractometer using MoK $\alpha$ radiation $(0.71073 \AA)$ monochromated by graphite.

The cell determination and the final cell parameters of $\mathbf{B i}-\mathbf{1}$, Bi-2, and Zn-1 were obtained on all reflections using the software CrystalClear. ${ }^{23}$ Data integration and scaling were carried out using the software Crystalclear ${ }^{23}$ and CrysAlisPro. $^{24}$ The structures were solved and refined with SHELXS-2013 ${ }^{25}$ software, included in WinGX ${ }^{26}$ and Olex2. ${ }^{27}$ Cell determination and final cell parameters of In-1 crystals were obtained on all reflections using the software Bruker SAINT included in the APEX2 software suite. ${ }^{28}$ Data integration and scaling were carried out using the software Bruker SAINT. ${ }^{27}$ In all cases, non-hydrogen atoms of the molecules were clearly resolved, and full-matrix least-squares refinements of these atoms with anisotropic thermal parameters were performed. Additionally, hydrogen atoms were stereochemically positioned and refined by the riding model. ${ }^{25}$ ORTEP diagrams for all structures were prepared with the Diamond ${ }^{29}$ program. TOPOS ${ }^{30}$ and Mercury ${ }^{31}$ programs were used in the preparation of the artwork of the polyhedral and topological representations. 


\subsection{Mechanical characterization}

Samples were prepared for mechanical characterizations including single crystals in acrylic resin (SUBITON®). Nanoindentation (NI) experiments were performed using an Agilent G200 Nano Indenter at room temperature. A Berkovich diamond tip with a final rounding of $20 \mathrm{~nm}$ was used in this study. The tip was calibrated using a standard fused silica sample. A group of 5 crystals was tested, and an array of $5 \times 5$ measurements up to a maximum penetration depth of $1200 \mathrm{~nm}$ was obtained for each selected crystal. The elastic modulus $(E)$ and hardness $(H)$ were calculated from the measurements by applying the Oliver \& Pharr model, which was described in our previous work. ${ }^{7}$

\subsection{Solid-state luminescence measurements}

The steady-state and time-resolved luminescence measurements were performed with an Edinburgh Instruments FLSP920 spectrometer setup, using a $450 \mathrm{~W}$ xenon lamp as the steady-state excitation source and an EPLED as the timeresolved excitation source with a fixed excitation wavelength of $331 \mathrm{~nm}$. The emission was detected with a Hamamatsu R928P photomultiplier tube (PMT). Excitation spectra were corrected for the xenon lamp emission profile, whereas emission spectra were corrected for the detector response curve. All measurements were carried out at a step size of $1 \mathrm{~nm}$.

\subsection{Catalytic activity}

Considering the nature of the new materials, among all possible organic transformations, only those that require a Lewis acid as catalyst were taken into account. Therefore, as a standard organic transformation, the cyanosilylation reaction (CSR) was chosen in order to evaluate the catalytic activity of Bi-1, Bi-2, and In-1 materials. In this order, catalytic amounts of the selected material $(0.5 \mathrm{~mol} \%, 1 \mathrm{~mol} \%$, and $2.5 \mathrm{~mol} \%$, respectively) were placed in a Schlenk tube under nitrogen atmosphere without solvents, together with the corresponding carbonyl compound ( 1 equivalent); trimethylsilyl cyanide (1.1 equivalent) was then added dropwise by syringe. The mixture was stirred until disappearance of the carbonyl compound; the kinetics of the reaction and its yield were confirmed by GC-MS.

\subsection{Antibacterial assays}

\subsection{Stock solutions of bismuth compounds}

Saturated aqueous solutions of the relatively insoluble compounds Bi-1, Bi-2, and bismuth citrate (Bi-cit) (Merck) were prepared in distilled and sterilized water by $0.22 \mu \mathrm{m}$-pore-size filters. Bi-cit was employed as a control because it is known as a bismuth derivative inhibitor of bacterial growth. ${ }^{17 b}$ The concentrations of the bismuth compounds were expressed as elemental bismuth as determined by total reflection X-ray fluorescence spectrometry (Bruker PicoFox S2 TXRF). Bi-NPs and Bi-cit concentrations used for this study depended on their limited water solubility.

\subsection{Bacterial strains and growth conditions}

The employed set of bacteria consisted of Escherichia coli (E. coli, strain K12), Salmonella enterica serovar Typhimurium (S. Typhimurium, strain LT2), and Pseudomonas aeruginosa (P. aeruginosa, strain PAO1). For assays with planktonic (free) cells, E. coli, $S$. Typhimurium, and $P$. aeruginosa were cultivated in Nutrient Broth (Difco) at a temperature of $37^{\circ} \mathrm{C}$. For biofilm assays, $P$. aeruginosa was grown in LB broth (10 $\mathrm{g}$ tryptone, $5 \mathrm{~g}$ yeast extract, and $5 \mathrm{~g} \mathrm{NaCl}$ in $1000 \mathrm{ml}$ distilled water) at $37{ }^{\circ} \mathrm{C}$.

\subsection{Effect of Bi-NPs on planktonic cultures and biofilm formation}

For assays with planktonic cultures, sterile Bi-compounds were serially suspended in tubes containing 1 milliliter of Nutrient Broth. Overnight cultures of the three bacterial strains were diluted $1 / 100$ in saline solution, and $100 \mu \mathrm{l}$ were added to each prepared tube as described. The tubes were incubated for $24 \mathrm{~h}$ at $37{ }^{\circ} \mathrm{C}$. Cell mass was evaluated by optical density at $650 \mathrm{~nm}$ wavelength $\left(\mathrm{OD}_{650}\right)$. Quantification of viable microorganisms was determined by colony counts of bacteria plated on Nutrient Agar (Difco) at $37^{\circ} \mathrm{C}$ and expressed as colony forming units per $\mathrm{ml}\left(\mathrm{CFU} \mathrm{ml} \mathrm{ml}^{-1}\right)$. Tubes without Bi-compounds were used as controls. For studies of biofilm formation, overnight cultures of $P$. aeruginosa were diluted $1 / 100$ in LB in a final volume of $100 \mu \mathrm{l}$ in the absence or presence of different concentrations of Bi-compounds in 96-well microplates. After $24 \mathrm{~h}$ incubation at $37{ }^{\circ} \mathrm{C}$ in a humidified chamber, planktonic cells were discarded and biofilm attached to the surface of the microplate wells was quantified by crystal violet staining. ${ }^{32}$

\subsection{Results}

\subsection{Synthesis}

After the followed procedure detailed in Scheme 1, the phases were characterized by PXRD and EDS in order to confirm their purity (see ESI section S4 and S5†). The morphological diversity was studied by SEM; growth habits were identified in Bi-1, Bi-2, and Zn-1; additionally, In-1 exhibited cubic crystals (Fig. 1). Good-quality crystals were carefully selected in order to perform SCXRD. The table in ESI section S6† summarizes the crystallographic data for all the synthesized compounds.

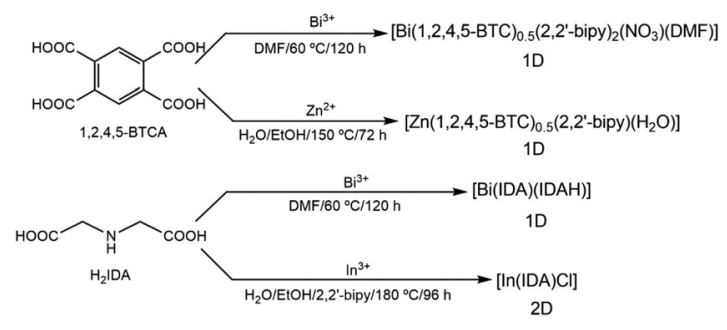

Scheme 1 Synthesis of the reported CPs. 

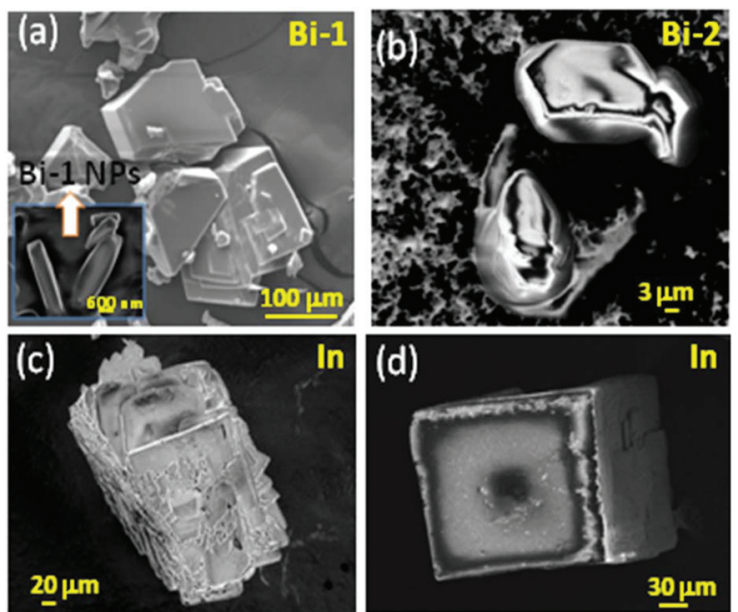

Fig. 1 Micrographs of (a) $\mathrm{Bi}-1$, (b) $\mathrm{Bi}-2$, and In-1 obtained (c) without and (d) with growth modulator.

\subsection{Crystal structure descriptions}

Bi-1 compound crystallizes in the triclinic $P \overline{1}$ space group. The primary building unit (PBU) consists of a nine-coordinated arrangement $\left(\mathrm{BiO}_{7} \mathrm{~N}_{2}\right)$, where seven oxygen atoms belong to 1,2,4,5-BTC, DMF, and nitrate, and two nitrogen atoms from the 2,2'-bipyridine form a trigonal prism square-face tricapped polyhedron (TPRS-9) ${ }^{33}$ (Fig. 2 left). As can be seen in Fig. 2 (right), the asymmetric unit of Bi-1 is composed of one trivalent $\mathrm{Bi}$ cation, one nitrate anion, one DMF, and one 2,2'bipyridine, in addition to a half of a crystallographically independent 1,2,4,5-BTC ligand.

In this compound, each $1,2,4,5$-BTC ligand is coordinated to four Bi centers in chelate $\eta^{2}$ mode, giving rise to chains along the $\left[\begin{array}{lll}1 & 0 & 0\end{array}\right]$ direction (Fig. 3 left) with intermetallic distances of 6.3594(6) and 9.3852(7) A. The Bi-O bond lengths are in the range $2.326(5)-2.77(1) \AA$, which were seen in analogous Bi-MOFs. ${ }^{14}$

The crystal structure of Bi-1 was analyzed with the TOPOS program in order to determine the underlying topology ${ }^{34}$ of the associated simplified net. Through this simplification, it is possible to observe that the carboxylate ligand acts as a 4-connected node and the metal center acts as a bridge forming
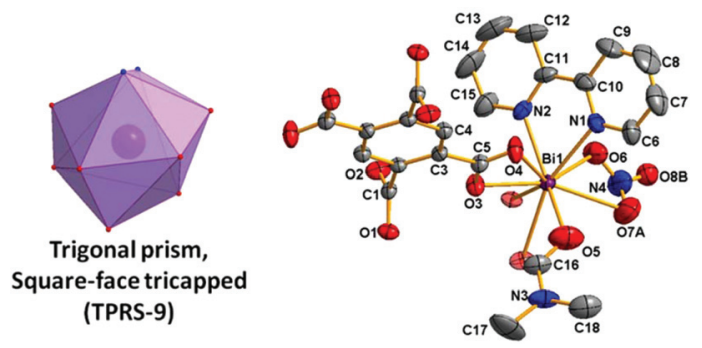

Fig. 2 Polyhedron representation of the PBU (left) and 50\% probability thermal ellipsoid diagram showing Bi-1 (right). Hydrogen and disordered atoms were omitted for clarity.

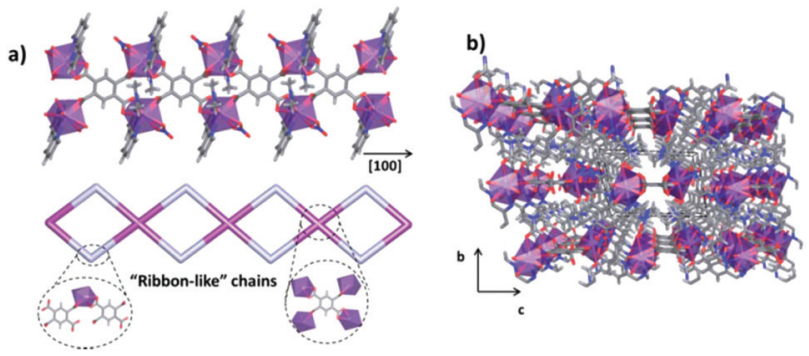

Fig. 3 (a) Polymeric chain and decorated simplified chain along the [1 0 0] direction and (b) crystal packing view into the $b c$ plane of $\mathrm{Bi}-1$ compound.

"ribbon-like" chains (Fig. 3 left). In addition, the compound can be classified as $\mathrm{I}^{0} \mathrm{O}^{1}$ according to the proposed classification suggested by Cheetham et $a .^{35}$ describing "coordination polymeric chains".

The 3D supramolecular structure (Fig. 3) is based on weak hydrogen bonds that join the chains along the [0 $\left.\begin{array}{lll}0 & 1 & 0\end{array}\right]$ and $\left[\begin{array}{lll}0 & 0 & 1\end{array}\right]$ directions, with distances C9-H9...O6 $=3.248(1)$ and $\mathrm{C} 18-\mathrm{H} 18 \mathrm{~A} \cdots \mathrm{Cg}=3.460(2) \AA ̊$, respectively $(\mathrm{Cg}$ ring $=\mathrm{C} 2, \mathrm{C} 3, \mathrm{C} 4$, $\left.\mathrm{C} 2{ }^{*}, \mathrm{C} 3^{*}, \mathrm{C} 4^{*}\right)$.

For comparative purposes, the $\mathbf{Z n - 1}$ compound ${ }^{36,37}$ was obtained. A deeper crystallographic description can be found in ESI section S7. $\dagger$ Similarly to Bi-1, here, the 1,2,4,5-BTC ligand is coordinated to four metallic centers giving rise to "ribbon-like" chains along the $\left[\begin{array}{lll}1 & 0 & 0\end{array}\right]$ direction, with intermetallic distances of 7.6958(7) and 8.0797(8) ^ (Fig. 4a). Despite presenting different coordination numbers, both compounds exhibit a similar arrangement of the ligand, giving rise to $1 \mathrm{D}$ coordination polymers.

Bi-2 was obtained as a crystalline solid belonging to the monoclinic $C 2 / c$ space group. The asymmetric unit is formed by one crystallographically independent trivalent $\mathrm{Bi}$ cation and two structurally different types of iminodiacetate ligand (IDA and protonated IDAH). The PBU can be described as an 8-coordinated metal center $\left(\mathrm{BiO}_{7} \mathrm{~N}\right)$ formed by seven oxygens and one nitrogen atom from the ligands, forming a square anti-

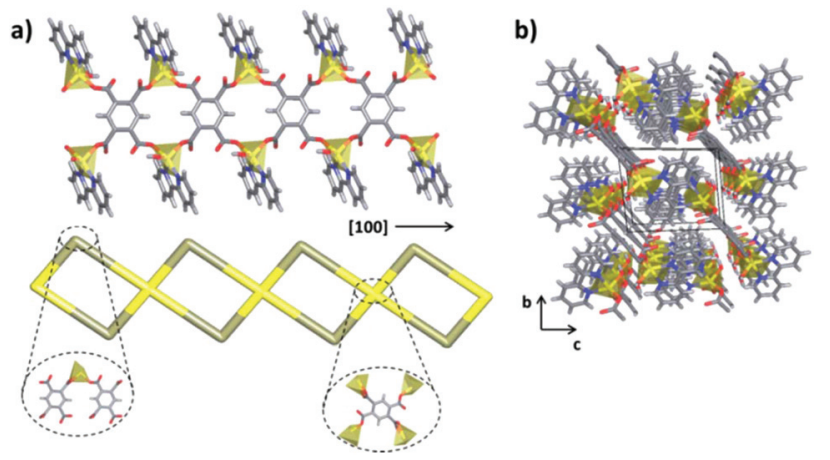

Fig. 4 (a) Polymeric chain and decorated simplified chain along the [ $\left.\begin{array}{lll}1 & 0 & 0\end{array}\right]$ direction and (b) crystal packing view into the bc plane of $\mathbf{Z n - 1}$ compound. 


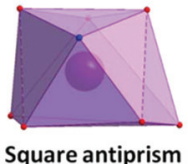

(SAPR-8)

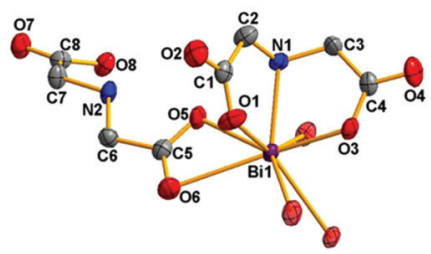

Fig. 5 PBU representation of the $\mathrm{Bi}^{3+}$ cation (left) and $50 \%$ probability thermal ellipsoid diagram showing for $\mathrm{Bi}-2$ (right). Hydrogen and disordered atoms were omitted for clarity.

prism polyhedron (SAPR-8) arrangement. In this case, the metal centers are joined by the ligand-forming dimeric edgesharing secondary binding units ( $\mathrm{SBUs})\left(\mathrm{Bi}_{2} \mathrm{~N}_{2} \mathrm{O}_{12}\right)$, with an intermetallic distance of 3.9612(9) $\AA$. The formation of the dimeric SBUs is due to the $\mu \eta_{2}$ and $\mu_{2} \eta_{2}$ coordination modes of the carboxylate groups (see ESI section S8 $\dagger$ ).

In the extended structure, the IDA acts as a tridentated ligand blocking the coordination sphere of the $\mathrm{Bi}^{3+}$, while the IDAH ligands join the SBUs along the $\left[\begin{array}{lll}0 & 0 & 1\end{array}\right]$ direction, giving rise to ribbon-like chains (Fig. 5 left and ESI section S8 $\dagger$ ). Additionally, the IDAH ligands join two metallic centers forming dimeric SBUs, acting as 4-connected nodes. The 3D supramolecular crystal packing (Fig. 5 right) is given by hydrogen bonds along the $\left[\begin{array}{lll}1 & 0 & 0\end{array}\right]$ direction, with distances $\mathrm{N} 1-\mathrm{H} 1 \cdots \mathrm{O} 4=2.932(6)$ and $\mathrm{C} 2-\mathrm{H} 2 \mathrm{C} \cdots \mathrm{O} 2=3.175(8) \AA$. Similar interactions are involved along the $\left[\begin{array}{lll}0 & 1 & 0\end{array}\right]$ direction, with distances N2-H2B $\cdots \mathrm{O} 2=2.908(7)$ and N2-H2A $\cdots \mathrm{O} 4=3.091(6) \AA$.

The 3D supramolecular structure is formed by strong hydrogen bonds and $\pi-\pi$ stacking interactions with distances O5-H5A $\cdots \mathrm{O} 1=2.657(3)$ and $\mathrm{Cg} \cdots \mathrm{Cg}=3.758(2) \AA$, along the $\left[\begin{array}{lll}0 & 0 & 1\end{array}\right]$ and $\left[\begin{array}{lll}0 & 1 & 0\end{array}\right]$ directions, respectively.

In-1 crystallizes in the Pnma orthorhombic space group. The metal environment is formed by one $\mathrm{Cl}$ atom, one nitrogen, and four oxygen atoms, giving rise to a distorted octahedral geometry (Fig. 6 left). The asymmetric unit is formed by a half of the $\mathrm{In}^{3+}$ cation, chloride anion, and IDA ligand. The ORTEP diagram of In-1 is displayed in Fig. 7 right. Each ligand is coordinated in $\mu_{3}$ chelate fashion through the protonated nitrogen atom and two oxygen atoms of the carboxylate group. Moreover, the carboxylate group exhibits a $\mu \eta^{2}$ coordination mode, linking a pair of metallic centers (intermetallic distance = 5.645(2) $\AA$ ) along the $\left[\begin{array}{lll}0 & 1 & 1\end{array}\right]$ and $\left[\begin{array}{lll}0 & -1 & -1\end{array}\right]$ directions (Fig. 8).

The junction of the metallic centers gives rise to layers in the (011) plane. As far as we know, this structure was topologically analyzed for the first time. In this case, each metal acts as a 4-connected node joined by the ligand, forming a $\mathbf{s q l}$ / Shubnikov topology net with point symbol $\left(4^{4} \cdot 6^{2}\right)$ (Fig. $8 \mathrm{~b}$ ). The 3D supramolecular structure is formed by the $\mathrm{Cl} \cdots \mathrm{H}-\mathrm{N}$ interaction with a distance of 2.719(6) A, which enables the stacking of the covalent layers along the $\left[\begin{array}{lll}1 & 0 & 0\end{array}\right]$ direction (Fig. 8c).

\subsection{Nanomechanical properties}

Dense CPs incorporate infinite inorganic connectivity, especially those based on metal-oxygen-metal motifs.

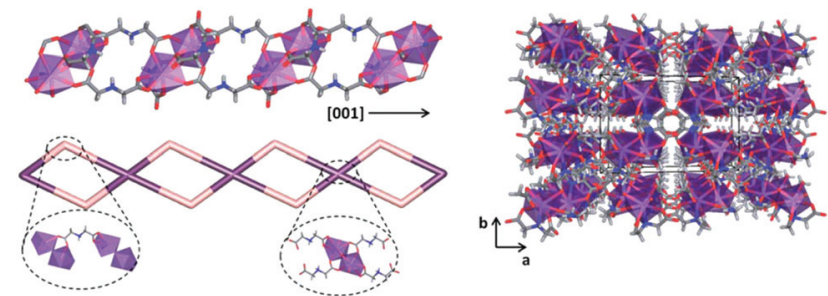

Fig. 6 Polyhedron and simplified representation of the chains (left) and crystal packing view along the [ $\left[\begin{array}{lll}0 & 0 & 1\end{array}\right]$ direction of $\mathrm{Bi}-2$ (right).

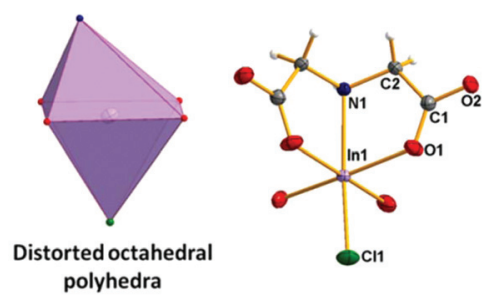

Fig. 7 Polyhedron representation of the $\ln ^{3+}$ (left) and 50\% probability thermal ellipsoid diagram for In-1 compound (right).

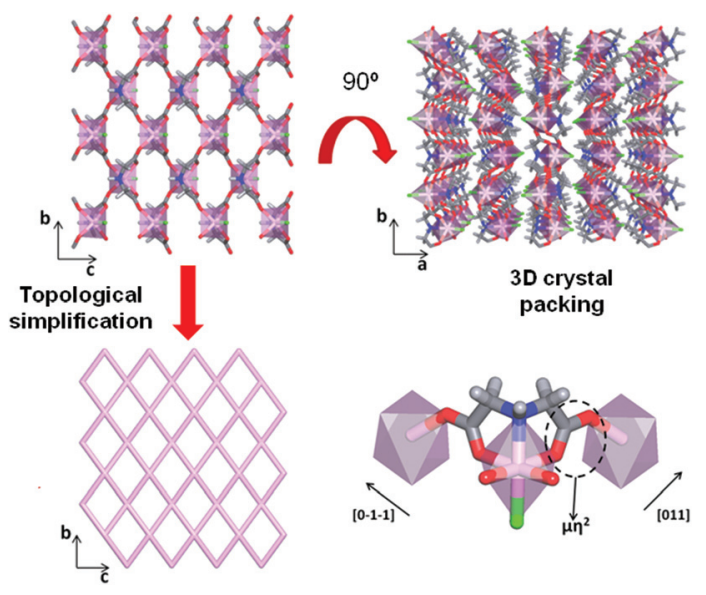

Fig. 8 (a) Representation of the 2D covalent network, (b) topological simplification, (c) 3D crystal packing, and (d) the coordination modes of the IDA ligand in In-1.

Recently, there has been an intense interest focused on CPs showing unique physical properties associated with their structures, which includes magnetic, electrical, optical, and multiferroic properties. Despite this, studies that have described the mechanical features of CPs are scarce. Additionally, good film stiffness and film-to-substrate adhesion strength is required for developing MOF/CP sensing devices. Moreover, elastic properties of the underlying framework are dominant in the performance of piezoelectric devices (such as actuators and sensors) and MOF coatings or membranes. ${ }^{38}$

In this context, there is special interest in the mechanical characterization of low-dimensional 1D or 2D frameworks due 

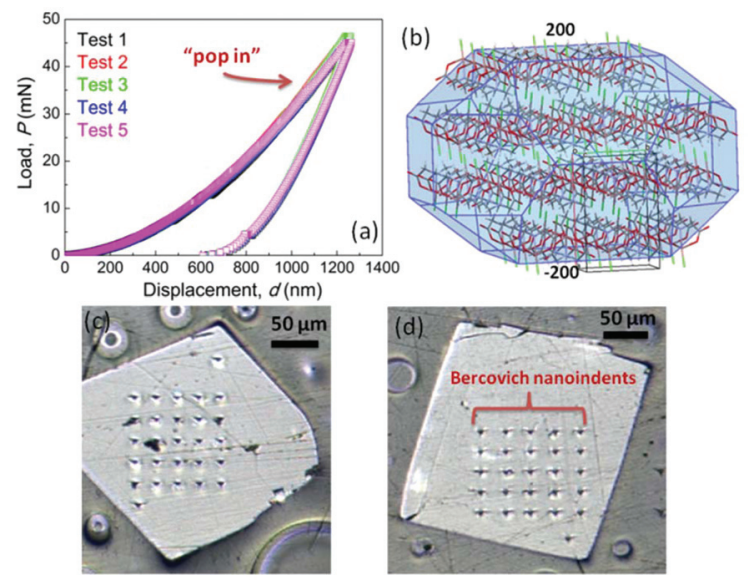

Fig. 9 (a) $P-h$ profiles of In-1 crystals. (b) Studied planes, in normal direction to the nanoindenter. (c and d) Indented cube crystals.

to the possibility of delamination ("top-down" fabrication) and further deposition onto different substrates in order to build membranes and thin-film composites. ${ }^{39,40}$ To elucidate structural-mechanical properties, NI experiments were performed on selected single crystals of In-1 and Bi-2 as representative models (Fig. 9a and 10a). In both cases, a $5 \times 5$ field of NI was applied to the single crystals. To avoid ambiguities, NI experiments on an acrylic substrate were performed (see displacement $(P-h)$ curves in ESI section S9 $\dagger)$ as a control experiment, obtaining $H$ and $E$ values of $0.11 \pm 0.01$ and $2.8 \pm 0.1 \mathrm{GPa}$, respectively.

The crystallographic planes that probabilistically are exposed in the In-1 compound, which are also coincident to those that divide the nanolayers, are the family of $h 00$ ones. In ESI section $\mathrm{S} 1, \uparrow$ a preferential orientation into the $\left[\begin{array}{lll}2 & 0 & 0\end{array}\right]$ planes is clearly identified. These planes are exposed by deposition of the layers, which are located in the direction in which non-covalent interactions ensure the packing of the layers (see
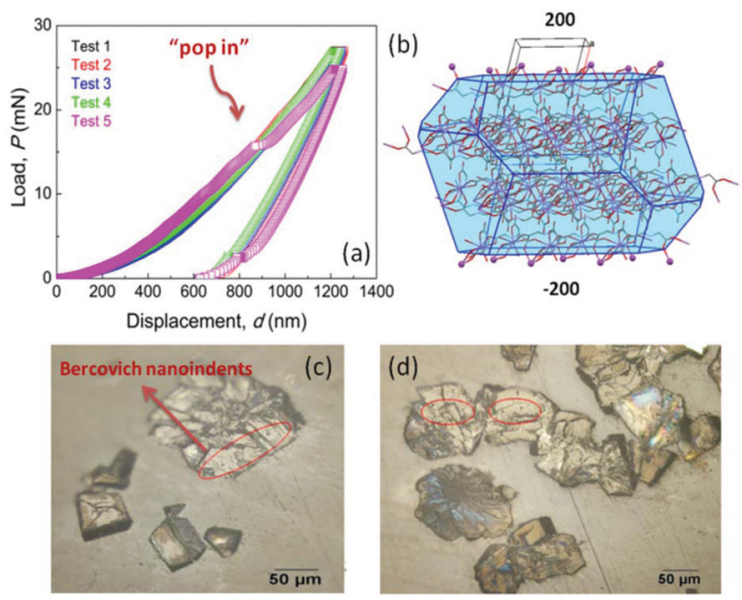

Fig. 10 (a) $P-h$ profiles of Bi-2 crystals. (b) Studied planes, in normal direction to the nanoindenter. (c and d) Indented single crystals.
Fig. 9b). The same family of 200 planes in Bi-2 (Fig. 10b) exposes a higher concentration of metallic polyhedral, conferring structural stiffness. As can be seen in Fig. 9, 10c and d, the "Berkovich marks" were identified after NI measurements.

The average values of $H$ and $E$ measured for In-1 were $1.8 \pm$ $0.1 \mathrm{GPa}$ and $24.3 \pm 0.8 \mathrm{GPa}$, respectively, and for $\mathbf{B i}-2$, were $1.1 \pm$ $0.1 \mathrm{GPa}$ and $12.4 \pm 0.5 \mathrm{GPa}$. The obtained values from $\mathbf{B i}-2$ are considerably lower compared to In-1, possibly because of a decrease in stiffness due to being one-dimensional.

It is important to note the presence of "pop-in", or displacement events, in the performed NI experiments, which appears due to the breakages of intermolecular weak bonds. Similar displacements have been reported in low-dimensional CPs such as $\left[\mathrm{Yb}_{2}(3-\mathrm{OHNDS})_{2}(1,10 \text {-phen })_{2}\left(\mathrm{H}_{2} \mathrm{O}\right)\right] \cdot 3 \mathrm{H}_{2} \mathrm{O}{ }^{7}$ $\left[\mathrm{Cu}\left(\mathrm{H}_{2} \mathrm{O}\right)_{2}\left(\mathrm{O}_{3} \mathrm{PCH}_{2} \mathrm{CO}_{2}\right)_{2}\right]^{41}$ and $[\mathrm{Mn}(2,2-\mathrm{dms})]^{40}$

According to the classification reported by Cheetham and colleagues, ${ }^{42}$ In-1 was located in the "dense hybrids" type materials and close to MOFs with similar mechanical performance (ESI section $10 \dagger$ ).

\subsection{Solid-state photoluminescence properties (SSPL)}

According to a significant number of specialized articles ${ }^{2}$ regarding photoluminescence (PL) properties, optical materials can be characterized by specific studies: (1) emission spectra (recorded as intensity vs. wavelength), (2) quantum yields (QYs), which refers to the efficiency of the luminescence process, and (3) the observed lifetime $\left(\tau_{\text {obs }}\right)$, which refers to the average time the molecule stays in its excited state before emitting a photon.

In contrast to the narrow and easily predictable emissions of $4 \mathrm{f}-4 \mathrm{f}$ transitions in rare earth elements, ${ }^{43}$ the PL in transition metals and MGE commonly exhibits broad bands. The excited states in TM- and MGE-based compounds are different from the ground state, and considerable anti-bonding often produces broad emissions and large Stokes shifts. Additionally, many types of PL might occur in the same compound, as it is a challenge to identify the electronic transitions.

LMCT (ligand to metal charge transition) might occur in TM and MGE-CPs with metals in high oxidation states; however, the assignment of LMCT in these compounds is often difficult, especially in mixed ligand systems. The most likely candidates for metal-centered emission are CPs containing $\mathrm{s}^{2}$-ions such as $\mathrm{Pb}^{2+}$ and $\mathrm{Bi}^{3+}$, where it is possible to observe $\mathrm{s}-\mathrm{p}$ transitions. ${ }^{44}$

The SSPL properties of $\mathbf{B i}-\mathbf{1}$ and $\mathbf{B i}-\mathbf{2}$ were studied by recording excitation-emission spectra, calculating lifetime values, and quantifying the color emission (QC) in comparison with the respective starting reactants $\left(\mathrm{Bi}\left(\mathrm{NO}_{3}\right)_{3}, \mathrm{H}_{2} \mathrm{IDA}\right.$, and $\left.\mathrm{H}_{4} \mathrm{BTC}\right)$. Usually, the spectroscopy of $\mathrm{Bi}^{3+}$ with $\mathrm{s}^{2}$ configuration in the ground state and sp configuration in the first excited state is discussed in Russell-Saunders-type electronic energy terms. Intense fluorescence emissions could be assigned to LMCT or the ${ }^{1} \mathrm{P}_{1} \leftarrow{ }^{1} \mathrm{~S}_{0}$ and ${ }^{3} \mathrm{P}_{1} \leftarrow{ }^{1} \mathrm{~S}_{0}$ transitions of the $\mathrm{s}^{2}$ electron of trivalent $\mathrm{Bi}^{3+}$ ions. ${ }^{45}$ In Bi-compounds, the dominant excitation transition is commonly ascribed to the population 
of the excited state ${ }^{3} \mathrm{P}_{1}$ from the ground state ${ }^{1} \mathrm{~S}_{0}$ (allowed by spin-orbit coupling), being that the ${ }^{3} \mathrm{P}_{0}$ level is strongly forbidden and a metastable state. At high temperatures, the emission ${ }^{1} \mathrm{P}_{1} \rightarrow{ }^{1} \mathrm{~S}_{0}$ transition is the most frequent in relation to the ${ }^{3} \mathrm{P}_{1} \rightarrow{ }^{1} \mathrm{~S}_{0}$ transition, and is evidenced as broad bands accompanied by splitting components. ${ }^{46}$

Therein, the emission peaks of $\mathbf{B i - 1}$ are located at longer wavelengths (446, 486, and $511 \mathrm{~nm}$ ) compared to Bi-2 (421, 435, and $464 \mathrm{~nm}$ ) (Fig. 11). The signal located at $511 \mathrm{~nm}$ in Bi1 could be attributed to $\pi \leftarrow \pi^{*}$ and/or $n \leftarrow \pi^{*}$ from 1,2,4,5-BTC and 2,2'-bipyridine ligands. For Bi-2, the contribution of the $\mathrm{n} \leftarrow \pi^{*}$ transition from the IDA carboxylate linker cannot be discounted. Moreover, it is remarkable that although the band splitting between both spectra is different, the intensities are similar. For an in-depth analysis, Zn-1 was obtained and compared to $\mathbf{B i - 1}$. Due to the fact that $\mathbf{Z n - 1}$ and $\mathbf{B i - 1}$ have the same set of coordinated ligands, both compounds exhibit broad bands. The phosphorescence-emitting bands were further analyzed by recording intensity decay curves (see ESI section $\mathrm{S} 11 \dagger)$, and luminescence lifetimes were calculated by fitting mono-exponential functions, $I=\mathrm{A} \exp \left(-t / \tau_{\text {obs }}\right)$. The corresponding yielded $\tau_{\text {obs }}$ were $16.7 \mu$ s and $0.52 \mu \mathrm{s}$ for Bi-1 and Bi-2, respectively. The $\tau_{\text {obs }}$ values of the Bi-CPs are higher compared to $\mathrm{Bi}\left(\mathrm{NO}_{3}\right)_{3}, \mathrm{H}_{2} \mathrm{IDA}$, and $\mathrm{H}_{4} \mathrm{BTC}(1.03,1.32$, and $1.02 \mathrm{~ns}$, respectively).

These differences might be related to their different coordination environment around $\mathrm{Bi}^{3+}$ ions, ${ }^{47}$ as $\mathrm{Bi}$ is nine-co-

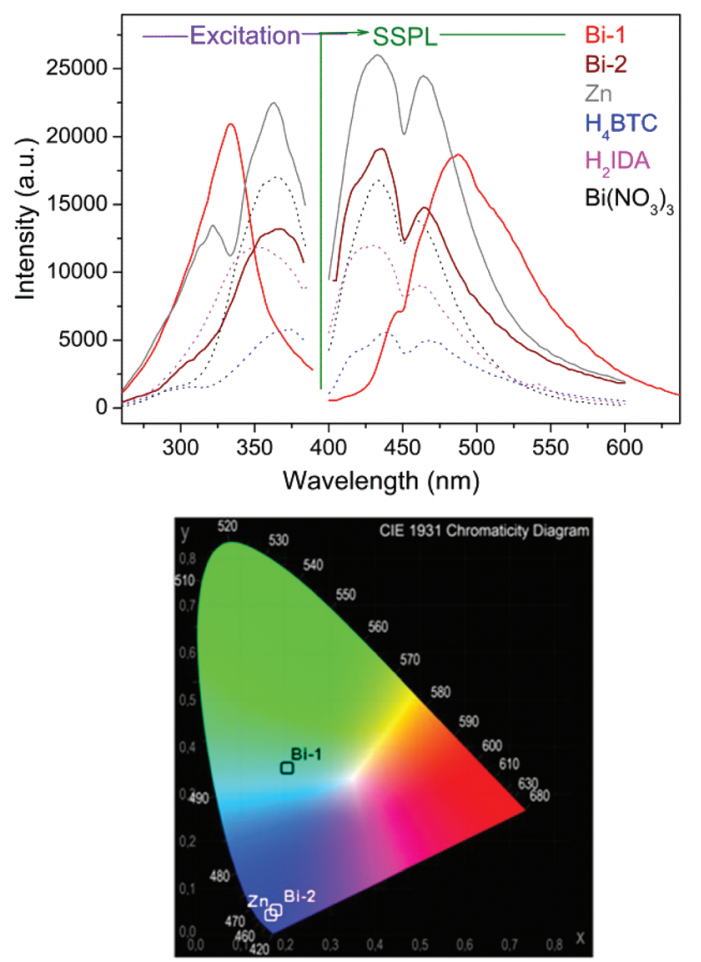

Fig. 11 Top: Excitation (left) and emission (right) spectra of Bi-CPs in comparison with $\mathrm{Bi}\left(\mathrm{NO}_{3}\right)_{3}, \mathrm{H}_{2} \mathrm{IDA}, \mathrm{H}_{4} \mathrm{BTC}$, and $\mathrm{Zn}-1$. Down: Chromaticities (CIE 1931) exhibited by Bi-1, Bi-2, and Zn-1. ordinated in Bi-1, while it is eight-coordinated in $\mathbf{B i - 2}$. The SSPL and excitation spectra of both Bi-CPs suggest that two different emission metal centers are responsible for the resultant luminescence components. It is noticeable that the two maximum peaks in the excitation spectra are shifted by $30 \mathrm{~nm}$, which is ascribed to the absorption of the bismuth-emitting center.

The QC for optical materials enables an accurate comparison between different materials based on their light-emitting performance. In this sense, the color coordinates are usually calculated employing the CIE (Commission International de L' Éclairage) system (ESI section S12†), proposed in $1931 .^{48}$ According to this approach, Bi-1 and $\mathbf{B i - 2}$ were identified with bluish green and bluish purple emissions, respectively (Fig. 11 bottom). In comparison, similar colorimetric and spectroscopic features were observed in analogous Bi-HPyr $\left(\mathrm{H}_{4} \mathrm{Pyr}=\right.$ 1,2,4,5-BTC), which exhibited pale green luminescence. ${ }^{47}$ Based on this analysis, Bi-1 and Bi-2 can be used as precursor materials for blue-light OLED/LED devices.

\subsection{Catalytic activity}

Cyanosilylation reactions (CSRs) are important carbon-carbon bond-forming processes that are catalyzed by Lewis acids/ bases that can be used as homogeneous ${ }^{49}$ or heterogeneous ${ }^{50}$ catalysts. Among all the alternatives, MOFs and CPs are good choices as heterogeneous catalysts for Lewis acid reactions due to their unique reactivity and selectivity under mild reaction conditions. . $^{8,10,13}$ Therefore, taking into account the excellent Lewis acid activity displayed by several In-MOFs reported in the literature, ${ }^{10,11,13}$ we decided to test the catalytic activity of $\mathbf{B i - 1}, \mathbf{B i}-\mathbf{2}$, and $\mathbf{I n - 1}$ in the cyanosilylation of acetophenone (Table 1).

It was found that the reactivity changes as a function of the metallic nature and the number of catalytic active sites pre-

Table 1 Screening of materials as catalysts for the cyanosilylation reaction using acetophenone as a carbonyl source

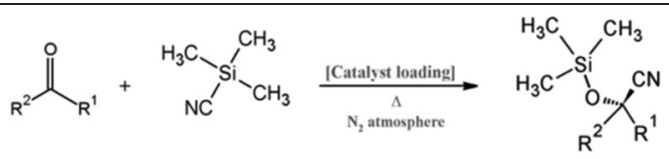

\begin{tabular}{llllrr}
\hline Material & $\begin{array}{l}\text { Metal CN } \\
\text { dimensionality }\end{array}$ & Topology & $\begin{array}{l}\text { Yield } \\
\text { time (h) }\end{array}$ & TOF $^{c}$ & TON $^{d}$ \\
\hline Bi-1 $^{a}$ & 9, 1D & Chain & $86(4)$ & 184 & 86 \\
Bi-2 $^{a}$ & 8, 1D & Chain & $70(4)$ & 33 & 70 \\
In-1 $^{a}$ & 6, 2D & sql & $96(4)$ & 76 & 96 \\
In-1 $^{e}$ & 6, 2D & sql & $98(4)$ & - & 40 \\
In-1 $^{f}$ & 6, 2D & sql & $90(6)$ & - & 180 \\
InBr $_{3}{ }^{g}$ & Salt & - & $90(3)$ & - & 90 \\
$($ ref. 51) & & & & & \\
Blank & N.A & N.A & $28(24)$ & N.A & N.A
\end{tabular}

${ }^{a}$ Solvent free reaction at $25{ }^{\circ} \mathrm{C}$ and $1 \mathrm{~mol} \%$ of catalyst under $\mathrm{N}_{2}$ atmosphere. ${ }^{b}$ Yields (GC-MS). ${ }^{c}$ TOF: $(\Delta \chi \times[\mathrm{mol}$ of reactant $/ \mathrm{mol}$ catalyst $] /$ $\Delta t) .{ }^{d}$ TON: $\left(\chi / \mathrm{mol}\right.$ catalyst). ${ }^{e}$ Reaction employing $2.5 \mathrm{~mol} \%$ of catalyst loading. ${ }^{f}$ Reaction employing $0.5 \mathrm{~mol} \%$ of catalyst loading. ${ }^{g}$ Homogeneous catalyst $[1 \mathrm{~mol} \%]$ using $\mathrm{CH}_{2} \mathrm{Cl}_{2}$ as solvent. 


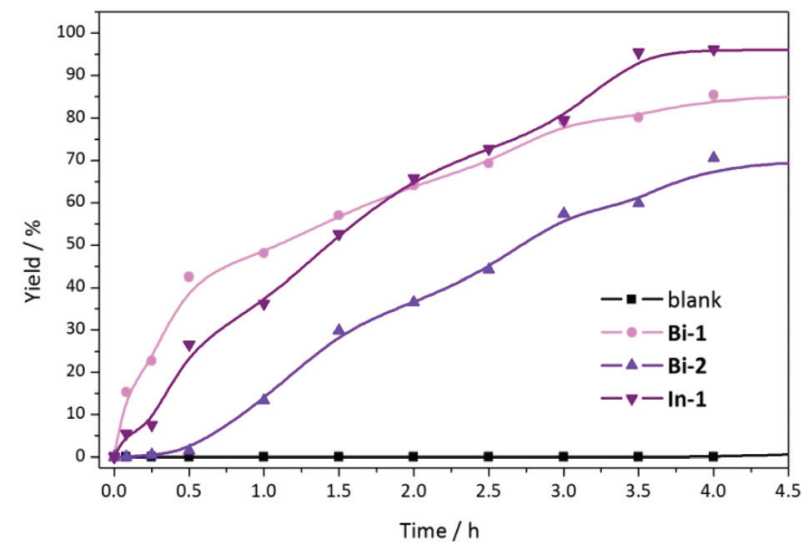

Fig. 12 Kinetic profiles of $\mathrm{Bi}-1, \mathrm{Bi}-2$, and In-1 catalysts in the cyanosilylation of acetophenone.

sented in each structure. The kinetic profile (Fig. 12) was studied to understand the catalytic performance of each material and to determine their turn over frequency (TOF) values.

The PXRD patterns of the recovered $\mathbf{B i}-\mathbf{2}$ and In-1 after the catalytic reactions indicate that these materials do not undergo any structural change. However, Bi-1 does not maintain its structural integrity after the catalytic reaction (see ESI, section $\mathrm{S} 13 \dagger)$, and will not be considered as a heterogeneous catalyst for use in further experiments.

From the data presented in Table 1, it is evident that a structure/catalytic ability relationship exists. The comparison between Bi-2 and In-1, which have the same organic linker in their structure, allows the study based on the nature of the metal cation. It would be expected that Lewis acid behavior follows the order of In-1 > Bi-2, based on the cation size impact of the acid strength. Additionally, indium catalyst with octahedral metal centers forms a covalent framework with higher dimensionality (2D layers) than Bi-2 (1D chains) material. This higher covalent disposition of In-1 clearly seems to favor the interaction between the available active sites of the catalyst with the substrates, even for those that are the most sterically hindered, as can be appreciated in Table 2 .

Table 2 Scope of the In-1 cyanosilylation of ketones ${ }^{a}$

\begin{tabular}{lllcc}
\hline Entry & Ketone & Time (h) & Yield $^{b}(\%)$ & TON $^{c}$ \\
\hline 1 & Acetophenone & 4 & 96 & 96 \\
2 & 4-Methylacetophenone & 8 & 89 & 89 \\
3 & 2-Methylacetophenone & 8 & 80 & 80 \\
4 & Cyclopentanone & 3.5 & 98 & 98 \\
5 & Cyclohexanone & 4 & 96 & 96 \\
6 & 4-Methylcyclohexanone & 4 & 97 & 97 \\
7 & 2-Hexanone & 3 & $>99$ & 99 \\
8 & 3-Hexanone & 3 & 85 & 85
\end{tabular}

${ }^{a}$ Solvent-free reaction at $25{ }^{\circ} \mathrm{C}$ and $1 \mathrm{~mol} \%$ of catalyst under $\mathrm{N}_{2}$ atmosphere. ${ }^{b}$ Product yields (GC-MS), and ${ }^{c}$ TON: ( $\chi /$ mol catalyst).
The scope of the reaction was studied for the cyanosilylation of ketones using In-1 as the catalyst (Table 2). In the case of non-aromatic ketones (Table 2, entries 4-8), higher yields were obtained compared to the aromatic ones (Table 2, entries 1-3). Reactions with linear aliphatic ketones (Table 2, entries 7 and 8) proceeded efficiently giving the corresponding product at shorter times with yields over $85 \%$. Higher yields of the cyclic ketones (Table 2, entries 4-6) were obtained (>97\%). Finally, satisfactory yields of the less reactive aromatic ketones were also obtained (80-96\%).

The results of the reactions carried out with acetophenone derivatives with electron-donating substituents, such as 2-methylacetophenone and 4-methylacetophenone, showed yields of $80 \%$ and $89 \%$, respectively.

The recyclability tests show that the In-1 material maintains its crystallinity even after ten catalytic cycles, with only a small decrease of its catalytic activity, probably due to the losses during the recovery of the catalyst (see ESI, section S14†). Hot filtration experiments revealed that In-1 is a truly heterogeneous catalyst.

\subsection{Antibacterial assays}

Firstly, the effects of Bi-NPs and Bi-cit on the cell growth of planktonic cultures of $E$. coli, $S$. Typhimurium, and $P$. aeruginosa were analyzed. Fig. 13 shows that $1.2 \mu \mathrm{g} \mathrm{ml} l^{-1}$ of
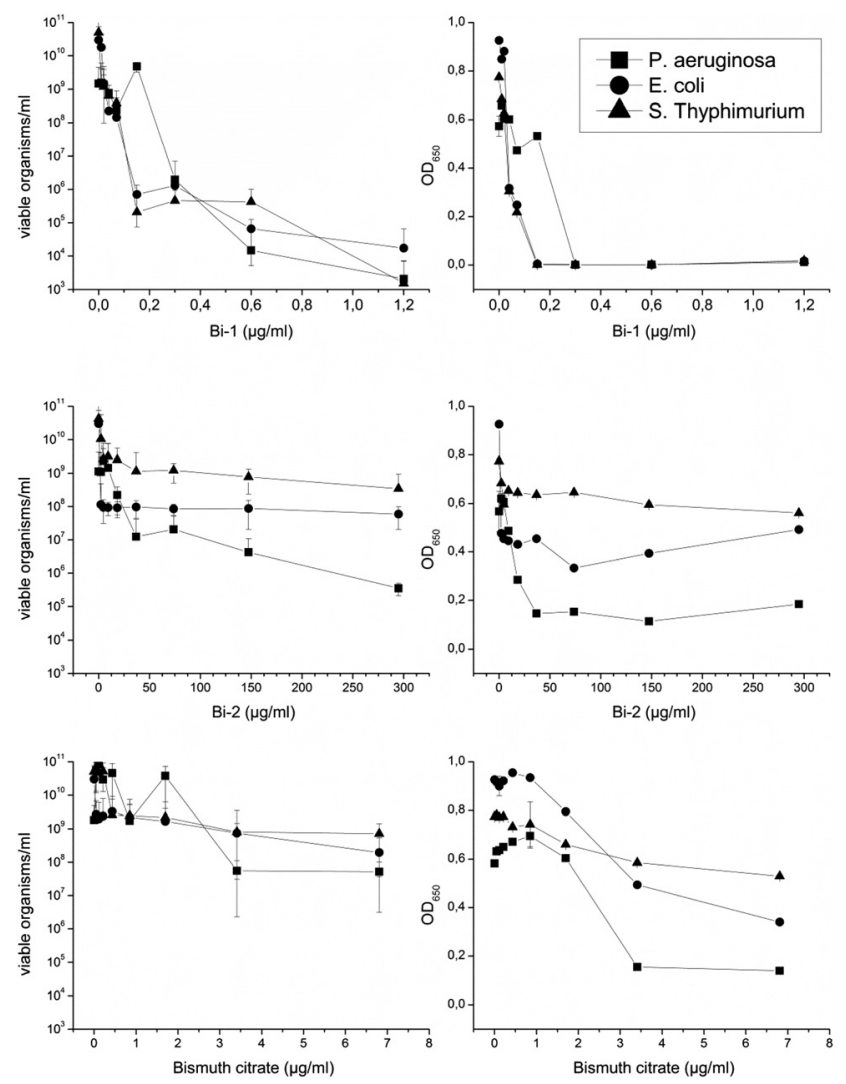

Fig. 13 Viable organisms per $m L$ and $\mathrm{OD}_{650}$ profiles of $\mathrm{Bi}-\mathbf{1}, \mathrm{Bi}-\mathbf{2}$, and Bi-cit. 
Table $3 \log _{10}$ reductions of bacterial viability produced by Bi-compounds compared to controls, according to the maximum concentration of compound used

\begin{tabular}{llll}
\hline Organism & $\begin{array}{l}\text { Bi-1 } \\
\left(1.2 \mu \mathrm{g} \mathrm{ml}^{-1}\right)\end{array}$ & $\begin{array}{l}\text { Bi-2 } \\
\left(295 \mu \mathrm{g} \mathrm{ml}^{-1}\right)\end{array}$ & $\begin{array}{l}\text { Bi-cit } \\
\left(6.8 \mu \mathrm{gl}^{-1}\right)\end{array}$ \\
\hline E. coli & 6 & 2 & 2 \\
S. Typhimurium & 7 & 2 & 2 \\
P. aeruginosa & 6 & 4 & 1.5
\end{tabular}

Bi-1 was required to decrease the amount of viable organisms by $6 \operatorname{logs}$ in E. coli and P. aeruginosa and by $7 \operatorname{logs}$ in $S$. Typhimurium (viable counts compared to controls). In contrast, $295 \mu \mathrm{g} \mathrm{ml}^{-1}$ of $\mathbf{B i}-2$ were required to reduce by $2 \operatorname{logs}$ the cell viability of $E$. coli and $S$. Typhimurium, and $4 \operatorname{logs}$ in P. aeruginosa (Fig. 13b). Bi-cit decreased cell viability 1.5-2 logs at $6.8 \mu \mathrm{g} \mathrm{ml}^{-1}$ in all the studied microorganisms (Fig. 13). Reduction of cell mass measured by $\mathrm{OD}_{650}$ followed the same observed tendencies as those for the cell viability (Fig. 13). According to these results, the greatest effect was produced by Bi-1, not only for the several orders of log reduction, but also for the lower concentration required to reduce bacterial growth (Table 3).

Then, the effect of Bi-NPs on the biofilm formation of $P$. aeruginosa was studied. P. aeruginosa is a relevant opportunistic pathogen of humans. Given its great capacity to form biofilms on diverse surfaces and cause severe damage to industry and human health, it is widely employed as a model in biofilm studies. Quantification of biofilms in control and test assays demonstrated that both Bi-NPs efficiently inhibited biofilm formation, although $\mathbf{B i}-\mathbf{1}$ produced its antibiofilm effect at lower concentrations than Bi-2 (Fig. 14a). In contrast with Bi-NPs, Bi-cit did not inhibit biofilm formation at concentrations $\leq 3 \mu \mathrm{g} \mathrm{ml} \mathrm{m}^{-1}$, but rather, it promoted its development. However, at higher concentrations, this effect

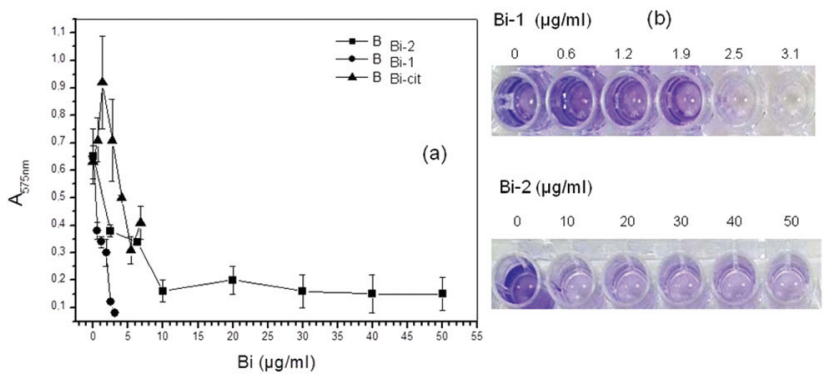

Fig. 14 (a) Effect of bismuth compounds on biofilm formation in $P$. aeruginosa. $P$. aeruginosa was grown in 96-well microplates in the absence or presence of different concentrations of Bi-NPs and bismuth citrate. Biofilms that adhered to the wells were subsequently stained with crystal violet, and the absorbance of the solubilized stain was measured at $575 \mathrm{~nm}$. Error bars represent the standard deviation of at least three independent experiments. (b) Visualization of biofilm formation in the absence or presence of different concentrations of Bi-NPs by crystal violet staining. Representative images are shown. was reversed and inhibition of biofilm formation was observed. Representative images of stained $24 \mathrm{~h}$ biofilms illustrate the inhibitory effect of Bi-NPs on biofilm formation (Fig. 14b). It is concluded that both Bi-NPs are effective antibiofilm agents in $P$. aeruginosa, with $\mathbf{B i - 1}$ being more powerful than Bi-2.

\subsection{Conclusions}

A set of CPs based on bismuth, indium, and zinc were successfully obtained. Due to the lack of studies regarding the structural, optical, mechanical, and antibacterial properties of CPs, an exhaustive analysis covering these topics was carried out. These compounds were synthesized from bismuth and indium salts (IDA, 1,2,4,5-BTC, and 2,2'-bipyridine) as building blocks. The one-dimensional Bi-CPs, $\left[\mathrm{Bi}(1,2,4,5-\mathrm{BTC})_{0.5}\left(2,2^{\prime}\right.\right.$-bipyridine)( $\left.\left(\mathrm{NO}_{3}\right)(\mathrm{DMF})\right]$ and [Bi(IDA)(IDAH)], belonged to $P \overline{1}$ and $C 2 / c$ space groups, and the layered In-CP, [In(IDA)Cl], belonged to the Pnma space group. Moreover, an in-depth analysis of the topology was carried out, where the Bi-CPs were simplified as "ribbon-like" chains, and a sql/Shubnikov tetragonal plane net with point symbol $\left(4^{4} \cdot 6^{2}\right)$.

To find relationships between the structural features and the intrinsic mechanical properties, nanoindentation studies were performed on a $1 \mathrm{D}$ and a layered compound (Bi-2 and In-1). The differences in the mechanical performances in both compounds were related to their crystal packing. According to $H$ and $E$ values, the CPs were located in the "dense hybrids" type of materials. These studies are important to evaluate the mechanical qualities of low-dimensional materials for device development.

The SSPL properties of the Bi-CPs were studied, which involved excitation-emission, lifetime experiments, and quantification of colour emission. Regarding these results, the Bi-CPs were classified as blue-emitters in the visible region, with performances comparable with analogous Bi-compounds and TM-MOFs. These optical features highlight the importance of Bi-CPs for the design of photonic devices with blue light emissions.

From our catalytic studies on these new CPs under solventfree conditions, we can conclude that the factor that drives the reaction yield relies on the metal nature and framework dimensionality. Therefore, the catalytic activity decreases in the following order: In-1 $>$ Bi-2. The In-1 material is capable of working as a real heterogeneous catalyst, using several hindered carbonyl derivates under mild reaction conditions and reaching high yields with a good recyclability rate.

Finally, the strong antibacterial effect of the Bi-CPs on E. coli, $S$. Typhimurium and $P$. aeruginosa was observed and compared to the well-known bismuth salt Bi-cit, especially in the case of Bi-1. The emergence and spread of antibiotic-resistant derivatives constitute a difficult problem that threatens the efficacy of treatment of many bacterial infections with antibiotics, and as a result, it is necessary to develop novel pathogen eradication methodologies. 


\section{Conflicts of interest}

There are no conflicts of interest to declare.

\section{Acknowledgements}

This work was supported by the Consejo Nacional de Investigaciones Científicas y Técnicas, ANPCyT PICT 20122087 and CNEA. G. E. G. acknowledges the postdoctoral CONICET fellowship and HYMADE project. R. D. acknowledges Coordenação de Aperfeiçoamento de Pessoal de Nível Superior for the CAPES/PNPD scholarship from the Brazilian Ministry of Education and Universidad Santiago de Cali. D. F. L. acknowledges doctoral CONICET fellowship. Ramón Castillo Guerra, Ricardo Montero, Guillermo Arnaldo, Rodrigo Taboada, and Gonzalo Zbihlei, from Departamento de Materiales - (CNEA), are gratefully thanked for helping with sample preparation for NI testing. L. M. A.-D., M. I. and M. A. M. acknowledge the Spanish Ministry of Economy, Industry and Competitiveness (MINECO-Spain) projects MAT2013-45460-R, MAT2014-52085-C2-2-P, MAT2016-78465-R, and CTQ2014-61748-EXP, Fondo Social Europeo from the European Union. Comunidad Autónoma de Madrid S2013/ MIT-2740 (PHAMA 2.0). R. V. D. and A. M. K. acknowledge Ghent University's Special Research Fund (BOF) for a Posdoctoral Mandate (project BOF15/PDO/091). J. E. is grateful to CNPq for the research fellowships. G. J. A. A. S. I. and M. C. F. are members of CIC-CONICET. Additionally, this project has received funding from the European Union's Horizon 2020 research and innovation program $\mathrm{H} 2020$ MSCA-RISE-2014, GA No. 645686.

\section{References}

1 N. L. Rosi, J. Eckert, M. Eddaoudi, D. T. Vodak, J. Kim, M. Okeeffe and O. M. Yaghi, Science, 2003, 300, 1127.

2 J. Heine and K. Müller-Buschbaum, Chem. Soc. Rev., 2013, 42, 9232.

3 (a) J.-L. Wang, C. Wang and W. Lin, ACS Catal., 2012, 2, 2630; (b) A. Corma, H. García and F. X. Llabrés i Xamena, Chem. Rev., 2010, 110, 4606.

4 (a) A. Thirumurugan and A. K. Cheetham, Eur. J. Inorg. Chem., 2010, 3823; (b) A. Thirumurugan, J.-C. Tan and A. K. Cheetham, Cryst. Growth Des., 2010, 10, 1736; (c) A. C. Wibowo, S. A. Vaughn, M. D. Smith and H.-C. zur Loye, Inorg. Chem., 2010, 49, 11001; (d) A. C. Wibowo, M. D. Smith and H.-C. zur Loye, CrystEngComm, 2011, 13, 426; (e) A. Thirumurugan, W. Li and A. K. Cheetham, Dalton Trans., 2012, 41, 4126; (f) L. Kan, J. Li, X. Luo, G. Li and Y. Liu, Inorg. Chem. Commun., 2017, 85, 70.

5 (a) M. Feyand, E. Mugnaioli, F. Vermoortele, B. Bueken, J. M. Dieterich, T. Reimer, U. Kolb, D. de Vos and N. Stock, Angew. Chem., Int. Ed., 2012, 124, 10519; (b) M. Feyand, E. Mugnaioli, F. Vermoortele, B. Bueken, J. M. Dieterich,
T. Reimer, U. Kolb, D. de Vos and N. Stock, Angew. Chem., Int. Ed., 2012, 52, 10373.

6 (a) G. E. Gomez, M. C. Bernini, E. V. Brusau, G. E. Narda, W. r A. Massad and A. Labrador, Cryst. Growth Des., 2013, 13, 5249; (b) R. F. D’Vries, G. E. Gomez, J. H. Hodak, G. J. A. A. Soler-Illia and J. Ellena, Dalton Trans., 2016, 45, 646; (c) G. E. Gomez, M. C. Bernini, E. V. Brusau, G. E. Narda, D. Vega, A. M. Kaczmarek, R. Van Deun and M. Nazzarro, Dalton Trans., 2015, 44, 3417.

7 R. F. D’Vries, G. E. Gomez, D. F. Lionello, M. C. Fuertes, G. J. A. A. Soler-Illia and J. Ellena, $R S C A d v .$, 2016, 6(111), 110171.

8 G. E. Gomez, A. M. Kaczmarek, R. Van Deun, E. V. Brusau, G. E. Narda, D. Vega, M. Iglesias, E. Gutierrez-Puebla and M. Ángeles Monge, Eur. J. Inorg. Chem., 2016, 2016(10), 1577.

9 R. F. D’Vries, V. A. de la Peña-O'Shea, N. Snejko, M. Iglesias, E. Gutiérrez-Puebla and M. A. Monge, J. Am. Chem. Soc., 2013, 135, 5782.

10 (a) L. M. Aguirre-Díaz, D. Reinares-Fisac, M. Iglesias, E. Gutiérrez-Puebla, F. Gándara, N. Snejko and M. A. Monge, Coord. Chem. Rev., 2017, 335, 1; (b) L. M. Aguirre-Díaz, M. Iglesias, N. Snejko, E. GutiérrezPuebla and M. A. Monge, RSC Adv., 2015, 5, 7058.

11 (a) R. F. D’Vries, S. Álvarez-García, N. Snejko, L. E. Bausá, E. Gutiérrez-Puebla, A. de Andrés and M. A. Monge, J. Mater. Chem. C, 2013, 1(39), 6316; (b) R. F. D'vries, M. Iglesias, N. Snejko, E. Gutiérrez-Puebla and M. A. Monge, Inorg. Chem., 2012, 51, 11349-11355.

12 (a) G. E. Gomez, E. V. Brusau, A. M. Kaczmarek, C. MellotDraznieks, J. Sacanell, G. Rousse, R. Van Deun, C. Sanchez, G. E. Narda and G. J. A. A. Soler-Illia, Eur. J. Inorg. Chem., 2017, 2017(17), 2321; (b) A. A. Godoy, G. E. Gomez, A. M. Kaczmarek, R. Van Deun, O. J. Furlong, F. Gándara, M. A. Monge, M. C. Bernini and G. Narda, J. Mater. Chem. C, 2017, 5, 12409-12421.

13 (a) L. M. Aguirre-Díaz, F. Gándara, M. Iglesias, N. Snejko, E. Gutiérrez-Puebla and M. A. Monge, J. Am. Chem. Soc., 2015, 137, 6132; (b) L. M. Aguirre-Díaz, M. Iglesias, N. Snejko, E. Gutiérrez-Puebla and M. A. Monge, Chem. Eur. J., 2016, 22, 6654; (c) D. Reinares-Fisac, L. M. AguirreDíaz, M. Iglesias, N. Snejko, E. Gutiérrez-Puebla, M. A. Monge and F. Gándara, J. Am. Chem. Soc., 2016, 138(29), 9089.

14 A. K. Inge, M. Köppen, J. Su, M. Feyand, H. Xu, X. Zou, M. O'Keeffe and N. Stock, J. Am. Chem. Soc., 2016, 138, 1970.

15 (a) X. X. Wang, B. Yu and K. Van Hecke, RSC Adv., 2014, 4(106), 61281-61289; (b) J.-M. Hao, L. N. Wang, K. Van Hecke and G.-H. Cui, Inorg. Chem. Commun., 2014, 41, 4346; (c) J.-M. Hao, B.-Y. Yi, K. Van Hecke and G.-H. Cui, CrystEngComm, 2015, 17, 2279-2293; (d) L.-M. Zhang, D.-Y. Deng, G. Peng, L. Liang, G.-Q. Lan and H. Deng, CrystEngComm, 2012, 14, 8083-8089.

16 G. R. Rudramurthy, M. K. Swamy, U. R. Sinniah and A. Ghasemzadeh, Molecules, 2016, 21, 836. 
17 (a) D. Mahony, S. Lim-Morrison, L. Bryden, G. Faulkner, P. Hoffman, L. Agocs, G. Briand, N. Burford and H. Maguire, Antimicrob. Agents Chemother., 1999, 43, 582; (b) J. R. Lambert, Rev. Infect. Dis., 1991, 13, 691; (c) M. D. Manhart, Rev. Infect. Dis., 1990, 12, 11; (d) A. M. Pitz, G. W. Park, D. Lee, Y. L. Boissy and J. Vinjé, Gut Microbes, 2015, 6(2), 93; (e) D. M. Keogan and D. M. Griffith, Molecules, 2014, 19, 15258.

18 C. Cabral and C. Shankararaman, Bismuto nanoparticles: antimicrobials of broad spectrum, low cost and safety, in Nanomedicine, ed. A. Seifalian, A. de Mel and D. M. Kalaskar, Publisher One Central Press (OCP), 2014, ch. 17, p. 430.

19 R. Hernández-Delgadillo, D. Velasco-Arias and D. Diaz, Zerovalent bismuto nanoparticles inhibit Streptococcus mutans growth and formation of biofilm, Int. J. Nanomed., 2012, 7, 2109-2113.

20 R. Hernández, D. Velasco, J. J. Martínez, D. Diaz, I. Zumeta, K. Arevalo and C. Cabral, Int. J. Nanomed., 2013, 8, 1645.

21 (a) A. Rajasekar, B. Anandkumar, S. Maruthamuthu, Y. P. Ting and P. K. Rahaman, Appl. Microbiol. Biotechnol., 2010, 85, 1175; (b) P. Gupta, S. Sarkar, B. Das, S. Bhattacharjee and P. Tribedi, Arch. Microbiol., 2016, 198, 1; (c) T.-F. C. Mah and G. A. O'Toole, Trends Microbiol., 2001, 9, 34.

22 J. C. Tan, J. D. Furman and A. K. Cheetham, J. Am. Chem. Soc., 2009, 131, 14252.

23 CrystalClear, 2.0 ed, Rigaku Corporation, Tokyo, Japan, 2005.

24 CrysAlisPro, Ltd, A. T., Ed, Agilent Technologies Ltd, Yarnton, Oxfordshire, England, 2014.

25 G. Sheldrick, Acta Crystallogr., Sect. A: Found. Crystallogr., 2008, 64, 112.

26 L. Farrugia, J. Appl. Crystallogr., 2012, 45, 849.

27 O. V. Dolomanov, L. J. Bourhis, R. J. Gildea, J. A. K. Howard and H. Puschmann, J. Appl. Crystallogr., 2009, 42, 339.

28 Bruker-AXS, I., 2 ed, Madison, WI, 2006.

29 H. P. K. Brandenburg, in DIAMOND, ed. Impact C., Crystal Impact, Kreuzherrenstr. 102, 53227 Bonn, Germany, 2006.

30 V. A. Blatov, A. P. Shevchenko and D. M. Proserpio, Cryst. Growth Des., 2014, 14, 3576.

31 C. F. Macrae, I. J. Bruno, J. A. Chisholm, P. R. Edgington, P. McCabe, E. Pidcock, L. Rodriguez-Monge, R. Taylor, J. Van De Streek and P. A. Wood, J. Appl. Crystallogr., 2008, 41, 466 .

32 J. H. Merritt, D. E. Kadouri and G. A. O’Toole, Curr. Protoc. Microbiol. Unit 1B.1, 2005, pp. 1B.1.1-1B.1.17.

33 N. G. Connelly, T. Damhus, R. M. Hartshorn and A. T. Hutton, Nomenclature of Inorganic Chemistry - IUPAC Recommendations 2005, RSC Publishing, Cambridge, UK., 2005.

34 (a) E. V. Alexandrov, V. A. Blatov, A. V. Kochetkov and D. M. Proserpio, CrystEngComm, 2011, 13, 3947; (b) M. O'Keeffe and O. M. Yaghi, Chem. Rev., 2012, 112, 675.

35 A. K. Cheetham, C. N. R. Rao and R. K. Feller, Chem. Commun., 2006, 4780.

36 R. Prajapati, L. Mishra, K. Kimura and P. Raghavaiah, Polyhedron, 2009, 28, 600.

37 X. Xu, Y. Lu, E. Wang, Y. Ma and X. Bai, J. Mol. Struct., 2006, 825, 124.

38 (a) F. Mammeri, E. Le Bourhis, L. Rozes and C. Sanchez, J. Mater. Chem., 2005, 15, 3787; (b) D. Zacher, O. Shekhah, C. Woll and R. A. Fischer, Chem. Soc. Rev., 2009, 38, 1418; (c) R. Ameloot, L. Stappers, J. Fransaer, L. Alaerts, B. F. Sels and D. E. De Vos, Chem. Mater., 2009, 21, 2580; (d) A. S. Huang, H. Bux, F. Steinbach and J. Caro, Angew. Chem., Int. Ed., 2010, 49, 4958.

39 Y. Peng, Y. Li, Y. Ban, H. Jin, W. Jiao, X. Liu and W. Yang, Science, 2014, 346, 1356.

40 J.-C. Tan, P. J. Saines, E. G. Bithell and A. K. Cheetham, ACS Nano, 2012, 6, 615.

41 J. C. Tan, C. A. Merrill, J. B. Orton and A. K. Cheetham, Acta Mater., 2009, 57, 3481.

42 J. C. Tan and A. K. Cheetham, Chem. Soc. Rev., 2011, 40, 1059.

43 (a) R. F. D’Vries, M. Iglesias, N. Snejko, S. Alvarez-Garcia, E. Gutierrez-Puebla and M. A. Monge, J. Mater. Chem., 2012, 22, 1191; (b) R. Decadt, K. Van Hecke, D. Depla, K. Leus, D. Weinberger, I. Van Driessche, P. Van Der Voort and R. Van Deun, Inorg. Chem., 2012, 51, 11623; (c) D. Esquivel, A. M. Kaczmarek, C. Jiménez-Sanchidrián, R. Van Deun, F. J. Romero-Salguero and P. Van Der Voort, J. Mater. Chem. C, 2015, 3, 2909.

44 A. Vogler and H. Nikol, Pure Appl. Chem., 1992, 64, 1311.

45 X. H. Yu, H. H. Zhang, Y. N. Cao, Y. P. Chen and Z. Wang, J. Solid State Chem., 2006, 179, 247.

46 (a) D. M. A. Ranfagni, M. Bacci, G. Viliani and P. Fontana, Adv. Phys., 1983, 32, 823; (b) J.-G. Kang, H.-M. Yoon, G.-M. Chun, Y.-D. Kim and T. Tsuboi, J. Phys.: Condens. Matter, 1994, 6, 2101.

47 M. Feyand, M. Köppen, G. Friedrichs and N. Stock, Chem. Eur. J., 2013, 19, 12537.

48 G. Kickelbick, in Hybrid Materials, Wiley-VCH Verlag GmbH \& Co. KGaA, 2007, pp. 1-48.

49 (a) B. Y. Park, K. Y. Ryu, J. H. Park and S.-g. Lee, Green Chem., 2009, 11, 946; (b) N. Kurono, M. Yamaguchi, K. Suzuki and T. Ohkuma, J. Org. Chem., 2005, 70, 6530; (c) P. Saravanan, R. V. Anand and V. K. Singh, Tetrahedron Lett., 1998, 39, 3823.

50 (a) Y. Ogasawara, S. Uchida, K. Yamaguchi and N. Mizuno, Chem. - Eur. J., 2009, 15, 4343; (b) A. Procopio, G. Das, M. Nardi, M. Oliverio and L. Pasqua, ChemSusChem, 2008, 1, 916; (c) K. Iwanami, J.-C. Choi, B. Lu, T. Sakakura and H. Yasuda, Chem. Commun., 2008, 1002.

51 M. Bandini, P. Cozzi, A. Garelli, P. Melchiorre and A. Umani-Ronchi, Eur. J. Org. Chem., 2002, 3243. 